\title{
Synchronous anal squamous carcinoma and sigmoid adenocarcinoma
}

\author{
Khalil EIGendy, Munira AISuwailem, Amro Salem
}

Department of Colorectal Surgery, King Fahad Specialist Hospital, Dammam, Saudi Arabia

Correspondence to Khalil ElGendy,

k.m.elgendy@gmail.com

Accepted 23 October 2014

\section{DESCRIPTION}

A 70-year-old woman presented with acute onset of bleeding per rectum and constipation with no history of previous illness. Examination revealed fresh bleeding per rectum with a low lying rectal mass protruding through and infiltrating the anal canal. CT scanning was undertaken (figure 1), revealing that the clinically apparent anal lesion involved the anal canal as well as rectum, and extended to the mesorectum. A second mass was also identified at the junction between sigmoid and descending colon, with associated circumferential thickening. In addition, multiple lymph nodes in the perirectal, presacral, external and internal iliac, and right inguinal regions were noted; however, there was no evidence of distant metastases. MRI was performed confirming the CT findings with infiltration of the anal lesion into the mesorectum, levator ani and vagina (figure 2). MRI staging was
T4N2. The patient underwent colonoscopy demonstrating that the anal lesion extended $15 \mathrm{~cm}$ from the anal verge; the second lesion seen on CT scanning was noted in the sigmoid colon encompassing more than three quarters of the colonic luminal circumference (figure 3). Biopsies from the anal lesion revealed a moderately differentiated squamous cell carcinoma (SCC), while the sigmoid lesion was a moderately differentiated adenocarcinoma. The patient underwent anterior resection of the sigmoid cancer with end colostomy and closure of distal stump and pathological examination of the resected tumour revealed a pT2N0 adenocarcinoma of the sigmoid. Following recovery from the anterior resection, the anal SCC was treated with primary chemoradiotherapy.

Synchronous colonic adenocarcinomas are welldescribed and preoperative colonoscopy is considered standard practice, as the identification of

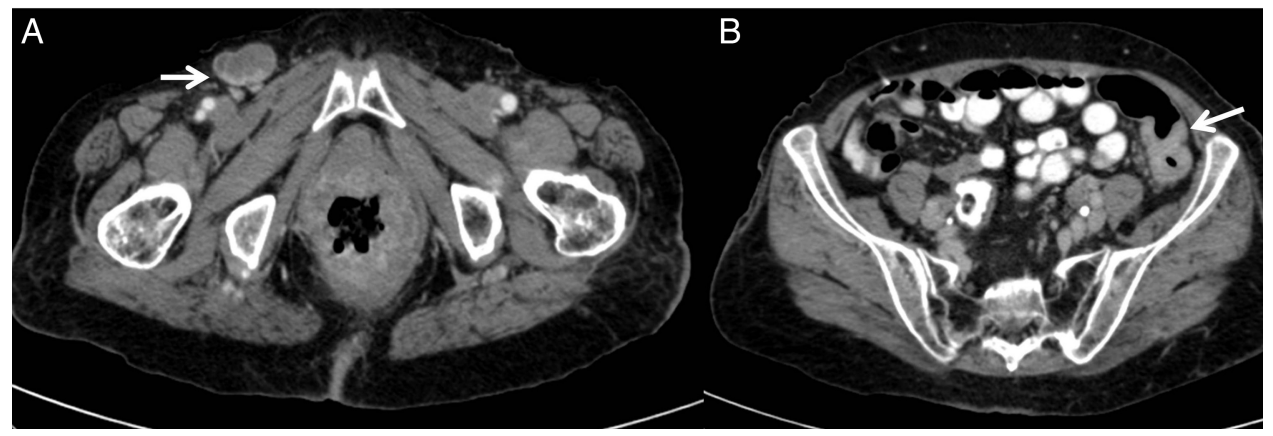

Figure $1 \mathrm{CT}$ of the abdomen and pelvis showing $(\mathrm{A})$ the circumferential anal mass with right inguinal lymph node metastasis (arrow) and (B) synchronous sigmoid lesion (arrow).

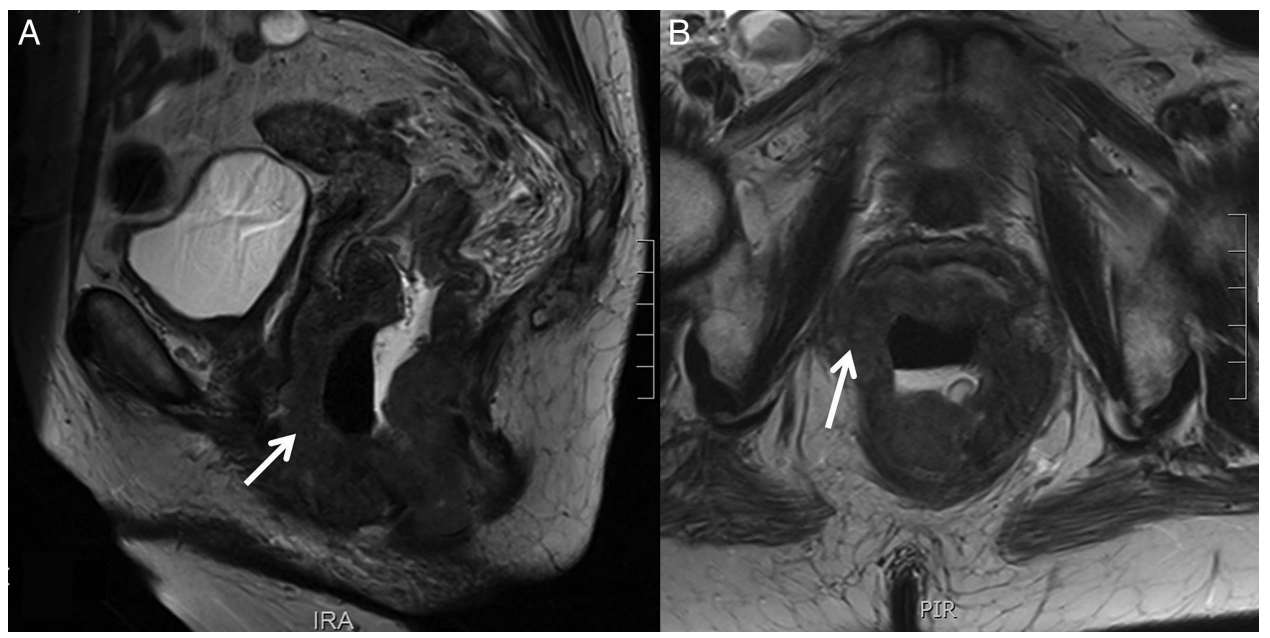

Figure $2 \mathrm{MRI}$ of the pelvis showing $(\mathrm{A})$ sagittal section and $(\mathrm{B})$ axial section demonstrating the anal mass (arrow) with infiltration to the rectum, vagina and levator ani. 


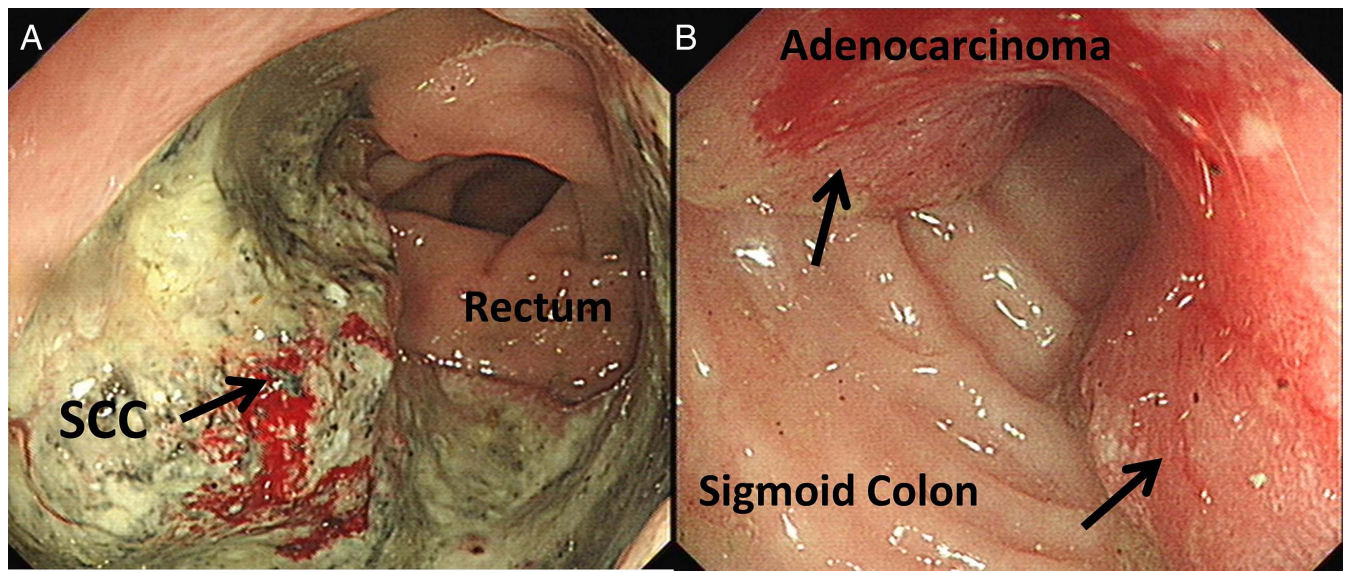

Figure 3 Colonoscopy showing (A) the anal squamous carcinoma (arrow) extending to the rectum and (B) the sigmoid mass (arrows) occupying more than half of the circumference of the colonic lumen.

\section{Learning points}

- Patients with anal cancer should undergo screening for colonic cancer or polyps, which might change the management course of these patients.

- Synchronous lesions of anal squamous carcinoma and colonic adenocarcinoma require a multidisciplinary team approach to establish the best management strategy for the patient.

- Current evidence suggests that anal cancer does not increase the incidence of colonic cancers, however, patients should undergo colonoscopy due to the incidence of colonic polyps in the age group of those presenting with anal squamous cell carcinoma (SCC).

- Further studies to establish the incidence of synchronous anal SCC with colonic polyps and adenocarcinoma is indicated to determine the value of colonoscopy, screening and surveillance in these patients.

further synchronous lesions will modify the planned surgical resection. In addition, the detection of associated polyps will determine the timing of planned colonoscopic follow-up. ${ }^{1}$ In contrast, synchronous SCC with a colonic adenocarcinoma is very rare and only one case report of synchronous anal SCC with colonic adenocarcinoma is currently published. ${ }^{2}$ The role of colonoscopy in patients with anal SCCs is unclear. Although anal cancer itself is not a risk factor for colon cancer, patients should, however, undergo colonoscopy due to the incidence of colonic polyps in the age group of those presenting with anal SCC and post-treatment surveillance of the colon should also be undertaken for this reason. ${ }^{1}$ For patients who have anal cancers, chemoradiotherapy is the recommended treatment following National Comprehensive Cancer Network (NCCN) guidelines ${ }^{3}$; however, the detection of synchronous colonic lesions will alter surgical management. Pretreatment colonoscopy of patients with anal SCC and a multidisciplinary team based management approach are required to ensure the most effective treatment strategies, optimal follow-up programmes and optimisation of long-term outcome of these patients.

Contributors KE involved in the literature review, manuscript and figure preparation, and discussion. MA involved in the data collection and case scenario. AS gave informed consent and was involved in the final revision.

Competing interests None.

Patient consent Obtained.

Provenance and peer review Not commissioned; externally peer reviewed.

\section{REFERENCES}

1 Barillari $\mathrm{P}$, Ramacciato $\mathrm{G}$, De Angelis $\mathrm{R}$, et al. Effect of preoperative colonoscopy on the incidence of synchronous and metachronous neoplasms. Acta Chir Scand 1990;156:163-6.

2 Weston SA, Wheeler WE. Synchronous squamous carcinoma of the anus and adenocarcinoma of the rectum. WV Med J 1992;88:9-10.

3 NCCN clinical practice guidelines in oncology: anal cancer, version 2. 2014. http:// www.nccn.org/professionals/physician_gls/PDF/anal.pdf

Copyright 2014 BMJ Publishing Group. All rights reserved. For permission to reuse any of this content visit

http://group.bmj.com/group/rights-licensing/permissions.

BMJ Case Report Fellows may re-use this article for personal use and teaching without any further permission.

Become a Fellow of BMJ Case Reports today and you can:

- Submit as many cases as you like

- Enjoy fast sympathetic peer review and rapid publication of accepted articles

- Access all the published articles

- Re-use any of the published material for personal use and teaching without further permission

For information on Institutional Fellowships contact consortiasales@bmjgroup.com

Visit casereports.bmj.com for more articles like this and to become a Fellow 